\title{
Longitudinal Ridge Split Osteotomy and Simultaneous Implant Placement
}

\author{
Stefan Peev ${ }^{1}$, Angela Gusiyska ${ }^{2}$, Elitsa Sabeva ${ }^{3}$ \\ ${ }^{1,3}$ Department of Periodontology and Dental Implantology, Medical University of Varna, Bulgaria \\ ${ }^{2}$ Department of Conservative Dentistry, Medical University of Sofia, Bulgaria
}

\begin{abstract}
Longitudinal ridge split osteotomy was performed in 33 cases with horizontal alveolar bone deficit, with a sufficient apical basis, that provides primary stability of the implants. The survival rate of the implants was $87,9 \%$. The mean marginal bone loss is $1.586 \mathrm{~mm}$. Bleeding on probing is registered in 45,5\% of the cases. There was found no correlation between the marginal bone loss and the bleeding on probing. The complication rate was 33,4\%. In 18,2\% of the cases was registered fracture of the vestibular bone plate.
\end{abstract}

Keywords: Longitudinal ridge split osteotomy, implants

\section{Introduction}

Because of their high survival and success rate, the intraosseal root-form dental implants are preffered as a method for treatment of edentulism. The disadvantage is that they require a sufficient bone volume-in horizontal and in vertical direction. One of the discussed alveolar bone augmentation methods is the longitudinal ridge split osteotomy,which is performed on a patients with horizontal alveolar bone deficit. The aim of this study is to evaluate the success rate and the predictability of the implants placed simultaneously with longitudinal ridge split osteotomy as a method for treatment of edentulism in the cases of insufficient alveolar bone volume.

Literature Survey

The longitudinal ridge split osteotomy is a longitudinal cut of the residual alveolar bone and dilatation of the fragments, which bases stay connected to the bone. As original the method is described with immediate implant placement (1). Some authors perform this method only in the upper jaw (2, $3,4)$, others - only in the mandible $(5,6)$, as the majority of the publications describe its performance in the both jaws $(7$, 8 ). The space between the two plates is filled with bonegrafting material, as some authors recommend the use of barrier membrane $(9,4)$, which covers them. Some authors report various intraoperative and early postoperative complications of the longitudinal ridge split osteotomy: inability to place the implant in the right position (9), loss of implants in the early postoperative period (before the implants are functional loaded) $(3,10,11)$, bone resorption around the implants $(12,2)$. In a systematic literature review Bassetti et al. (13) report survival rate of implants placed simultaneous with the longitudinal ridge split-osteotomy of $91,7 \%$ to $100 \%$, which is comparable with the results reported by some authors of implant placement in non augmentated bone or implants, placed simultaneoysly with guided bone regeneration.

\section{Methods}

Longitudinal ridge split osteotomy was performed in cases with horizontal alveolar bone deficit, with a sufficient apical basis, that provides primary stability of the implants. After the elevation of mucoperiosteal flap, pilot holes were done in the area of the planned implant positions. Then split osteotomy was done. One horizontal and two vertical cuts were done using piezosurgical device with graduated tip. The horizontal cut was made along the crest of the alveolar ridge and the vertical cuts were placed $1 \mathrm{~mm}$ from the adjacent teeth. The depth of the osteotomy is $3 \mathrm{~mm}$ shorter than the depth of the pilot holes - resp.the length of the placed implants. Two bone plates were obtained due to the osteotomy. The alveolar ridge was expanded trough the separation of the both bone plates. The osteotomy for the implant placement was enlarged to the desired diameter consecutively with increasing diameter twist drills. Then the implants were placed and the remaining space between the both plates was filled with bone grafting material. Also the vestibular bone plate was covered with bone grafting material and barrier membrane, which also covered the opening of the split-osteotomy.

The muco-periosteal flap was mobilized, repositioned and sutured using 5/0 monofilament polyamide thread (Dafilon, B.Braun-Melsungen,Germany). When intraoperative was observed insufficient stability of the vestibular plate, it was stabilized using microscrew.

In the cases of longitudinal ridge split osteotomy with simultaneous implant placement were observed the following criteria: presence of intraoperative and postoperative complications; the survival rate for the period of observation, bone resorption visible on radiography, bleeding on probing.

\section{Results}

The results are shown in app.16. The mean period of observation was 5 years.. The mean age of the patients was 38,45 years.. The most common area, where the procedure was performed is the anterior maxilla. The implants were functional loaded 4 months after the procedure. The survival rate of the implants was $87,9 \%$. The mean marginal bone loss was $1.586 \mathrm{~mm}$. Bleeding on probing was registered in $45,5 \%$ of the cases. There was found no correlation between the marginal bone loss and the bleeding on probing. The complication rate was $33,4 \%$. In $18,2 \%$ of the cases was 


\section{International Journal of Science and Research (IJSR) \\ ISSN (Online): 2319-7064}

Index Copernicus Value (2013): 6.14 | Impact Factor (2014): 5.611

registered fracture of the vestibular bone plate, which required fixation with microscrew and in $15,2 \%$ of the cases there was not achieved the correct/planned prosthetic position.

\section{Discussion}

The mean survival rate of the implants placed simultaneously with split ridge osteotomy according to our methodology is $87,9 \%$, which is lower than the survival rate of the implants placed according to other methods, which we have observed(14, 15, 16, 17). Chiapasco et al.(17, 18), Sethi and Kaus(19) reported higher survival rate and their results are similar to those of Engelke et al(1). The mean marginal bone loss is higher than the mean marginal bone loss of other methods, which were included in our study $1,586 \mathrm{~mm}(14,15,16,17)$. Although it is lower than the marginal bone resorption described by other authors(20). Unlike the other observed by us methods, between the higher rate of the bleeding on probing of the implants placed simultaneously with ridge split osteotomy $(45,5 \%)$ and the severity of the marginal bone loss was found no correlation. This is due to the typical for this procedure bone resorption, which is due to the increased intensity of the bone remodeling of the osteotomed bone plates, which leads to a dehiscence of the threaded surface of the implant. The threaded surface is plaque retentive, which leads to increased accumulation of bacterial plaque, that provokes inflammation.

\section{Conclusion}

The implants placed simultaneously with longitudinal ridge split osteotomy demonstrate the lowest survival rate, the highest mean marginal bone loss and the highest rate of periimplantitis ,compared to other methods, that we observed for implant treatment of a patients with insufficient bone volume of the alveolar crest. That's why we evaluate the ridge split osteotomy with simultaneous implant placement as a method with very low success rate and predictability.

\section{References}

[1] Engelke WG, Diederichs CG, Jacobs HG,Deckwer I. Alveolarreconstruction with splitting osteotomy and microfixation ofimplants. Int J Oral Maxillofac Implants 1997;12:310-318.

[2] Garcez-Filho J, Tolentino L, Sukekava F, Seabra M, Cesar-Neto JB, Araújo MG. Long-term outcomes from implants installed by using split-crest technique in posterior maxillae: 10 years of follow-up. Clin Oral Implants Res. 2015 Mar;26(3):326-31.

[3] Santagata M, Guariniello L, Tartaro G. Modified edentulous ridge expansion technique and immediate implant placement: a 3-year follow-up. J Oral Implantol. 2015 Apr;41(2):184-7. doi: 10.1563/AAIDJOI-D-12-00308.

[4] Gonzalez-Garcıa, R., Monje, F. \& Moreno, C. Alveolar splitosteotomy for the treatment of the severe narrow ridge maxillaryatrophy: a modified technique.
International Journal of Oral andMaxillofacial Surgery, 2011 40: 57-64.

[5] Rodriguez, J.G. \& Eldibany, R.M. Vertical splitting of themandibular body as an alternative to inferior alveolar nervelateralization. InternationalJournal of Oral and MaxillofacialSurgery 2013, 42: 1060-1066. ]

[6] Ella, B., Laurentjoye, M., Sedarat, C., Coutant, J.C.,Masson, E. \& Rouas, A. Mandibular ridgeexpansion using a horizontal bonesplitting technique and synthetic bone substitute: an alternativeto bone block grafting? The InternationalJournal of Oral and Maxillofacial Implantsq 2014, 29:135-140.

[7] Crespi, R., Cappare, P. \& Gherlone, E.F. Electrical mallet provides essential advantages in split-crest and immediate implant placement. Journal of Oral Maxillofacial Surgery 2014, 18: 59-64.

[8] Anitua, E., Begona, L. \& Orive, G. Clinicalevaluation of split-crest technique with ultrasonicbone surgery for narrow ridgeexpansion:status of soft and hard tissues and implantsuccess.Clinical Implant Dentistry and RelatedResearch, 2013, 15: 176-187.

[9] Tang YL, Yuan J, Song YL, Ma W, Chao X, Li DH. Ridge expansion alone or in combination with guided bone regeneration to facilitate implant placement in narrow alveolar ridges: a retrospective study. Clin Oral Implants Res. 2015 Feb;26(2):204-11.

[10] Langer, B., Langer, L. \& Sullivan, R.M. Planned labial plateadvancement with simultaneoussingle implant placement for narrowanterior ridges followed by reentry confirmation.InternationalJournal of Periodontics and Restorative Dentistry. 2012, 32: 509-519.

[11] Montero, J., Lopez-Valverde, A. \& de Diego, R.G. A retrospective study of the risk factors for ridge expansion with self-tapping osteotomes in dental implant surgery. The International Journalof Oral and Maxillofacial Implants 2012, 27: 203-210.

[12] Scipioni, A., Bruschi, G.B. \& Calesini, G. The edentulous ridge expansion technique: a fiveyear study. International Journal of Periodonticsand Restorative Dentistry 1994, 14: 451-459.

[13] Bassetti MA, Bassetti RG, Bosshardt DD. The alveolarridgesplitting/expansion technique: a systematic review.Clin. OralImpl. Res. 00: 2014, 1-15

[14] Peev S,Sabeva E, Gusiyska A, Georgiev T, Tonchev T,Long-term follow-up of Implants with Reduced Length.Scripta Scientifica Medicinae Dentalis, vol. 1, No2, 2015, pp. 49-52

[15]Peev S,Georgiev T, Sabeva E, PapanchevG, PanovV.Sinus floor elevation with lateral approach and five-year follow-up.Medinform. 2016; 3(1):370-379.

[16] Peev S., Sabeva E., Subperiosteal Implants in Treatment of Total and PartialEdentulism - A Long Term Follow Up,International Journal of Science and Research (IJSR), Volume 5 Issue 2, February 2016, 98-99

[17] Chiapasco M, Zaniboni M, Boisco M. Augmentation procedures for the rehabilitation of deficient edentulous ridges with oral implants.Clin. Oral Impl. Res.17(Suppl. 2), 2006; 136-159

[18] Chiapasco M., Casentini P., Zaniboni M.,Bone AugmentationProcedures in Implant Dentistry, INT J ORAL MAXILLOFACIMPLANTS 


\section{International Journal of Science and Research (IJSR) \\ ISSN (Online): 2319-7064}

Index Copernicus Value (2013): 6.14 | Impact Factor (2014): 5.611

[19] Sethi A, Kaus T.Maxillary ridge expansion with simultaneousimplant placement: 5-year results of an ongoing clinical study. Int J Oral Maxillofac Implants 2000;15:491-499.

[20] Stricker A, Fleiner J, Stubinger S, Schmelzeisen R, Dard M,Bosshardt DD. Bone loss after ridge expansion with orwithoutreflection of the periosteum. Clin. Oral Impl. Res. 26, 2015, 529-536

\section{Author Profile}

Stefan Peev DMD, PhD, DSc - Professor (Associate), Head of Department of Periodontology and Dental Implantology, Medical University of Varna, Bulgaria, Director of University Dental Clinic - Varna

Angela Gusiyska,DMD,PhD - Assistant Professor - Department of Conservative Dentistry, Medical University of Sofia, Bulgaria

Elitsa Sabeva DMD - Assistant Professor at Department of Periodontology and Dental Implantology, Medical University of Varna, Bulgaria 